\section{Should Emergency Pharmacists Focus on Providing Care to Admitted Patients Rather than Non-admitted Patients?}

\section{THE "PRO" SIDE}

Emergency pharmacists (EPhs) should give priority to patients requiring admission, both to improve patient outcomes and to reduce health care costs. ${ }^{1,2} \mathrm{I}$ am making this argument with recognition that prioritization will always be required, as there are many other valuable activities to which EPhs can devote their time. The prioritization of inpatients is paramount during the provision of pharmaceutical care in the emergency department (ED), to address the factors contributing to high risk for adverse drug events (ADEs) and medication errors, such as ED overcrowding, diversity of clinical presentations, use of high-risk medications, and high patient-health care provider ratios. $^{3}$

ED overcrowding has reached epidemic proportions, as a result of an imbalance between public demand and hospital capacity. ${ }^{4}$ It is associated with an increased risk for medication errors, which can be alleviated by the services that EPh provide. ${ }^{5}$ In Canada, about $11 \%$ of all $\mathrm{ED}$ visits result in inpatient admission. ${ }^{6}$ To put this statistic into perspective, about $60 \%$ of all hospital inpatients are admitted from the ED. ${ }^{6}$ Admitted patients' length of stay in the ED has been increasing steadily through the years, and patients can spend upward of $34 \mathrm{~h}$ in the ED awaiting a bed or transfer to another hospital. ${ }^{6}$ The American Society of Health-System Pharmacists ${ }^{7}$ endorses the concept that inpatient ward pharmacists be accountable for admitted patients, but adherence with this recommendation may not be feasible, depending on the location and acuity of individual patients. ED crowding with inpatients is often a direct result of overcapacity within the hospital, and inpatient ward pharmacists may not be able to provide timely pharmaceutical care because of their high existing workload. Brown and others ${ }^{8}$ were able to reduce medication errors involving ED patients with prospective pharmacy review by EPhs, which included dosage calculations; identification of inappropriate drugs, routes, or schedules; order clarifications; and drug allergy clarifications. ${ }^{8}$ Focusing the efforts of EPhs on patients who are being referred for admission is crucial, as these patients often have critical illnesses or urgent needs, and they represent high-risk populations. Through early, proactive involvement, $\mathrm{EPhs}$ can reduce the risk of medication errors.
The ED is characterized by a diversity of clinical presentations, and previous studies have supported the use of EPhs for timely administration of high-risk medications or procedures in acute phases of illness, such as cardiopulmonary resuscitation, pain management, sepsis management, procedural sedation, intubation, and antifibrinolytic therapy. ${ }^{9}$ Patients in need of such high-risk medications and procedures are often in critical, complex situations, have high pharmacotherapeutic needs, and are likely to be admitted. As such, EPhs should give them priority and be proactive in their management to improve patient outcomes. For example, rather than reactively identifying ADEs after admission orders have been processed, EPhs can proactively support the admission team at the time admission orders are prepared. This crucial role was apparent in a study showing that admitted patients seen by EPhs received more appropriate initial medication regimens, as reflected by a $75 \%$ reduction in interventions by ward pharmacists. ${ }^{10}$ Therefore, the ED is a good location for pharmacists to effectively identify and resolve preventable $\mathrm{ADEs}$ for patients who will be admitted with a diversity of presentations.

ADEs account for about $28 \%$ of all $\mathrm{ED}$ visits and $24 \%$ of hospital admissions. ${ }^{11}$ Furthermore, more than one-third of drugrelated ED presentations identified by pharmacists have been missed by emergency physicians. ${ }^{12}$ These cases are associated with longer hospital stays, greater mortality, and higher costs to the health care system. ${ }^{13}$ Most preventable ADEs that happen in the $\mathrm{ED}$ are attributed to improper medication reconciliation or to inappropriate medication orders. ${ }^{14}$ Therefore, Accreditation Canada has identified medication reconciliation as a priority for Canadian hospitals, which are expected to complete this process for all ED patients with a decision to admit. ${ }^{15}$ Pharmacist-led management of $\mathrm{ADEs}$ and preparation of admission drug histories have been associated with lower mortality rates. ${ }^{1}$ Importantly, EPhs are able to provide more accurate best possible medication histories (BPMHs) than other health professionals, and are associated with fewer medication errors. ${ }^{16}$ Thus, timely medication histories and identification of ADEs in the medication reconciliation process may result in admitted patients having an accurate medication regimen early in their hospital stay and early identification of medication-related events. Barriers to practice, such as insufficient time to perform medication reconciliation activities, may be overcome with adequate pharmacy staffing in the ED. This was made evident by a Canadian survey, in which only $23 \%$ of ED pharmacy teams surveyed reported that their 
EDs had adequate staffing, and $81 \%$ of ED managers expressed the need for additional staffing in the ED to allow proper completion of BPMHs. ${ }^{17}$

The issues described above — overcrowding of the $\mathrm{ED}$, driven by high numbers of admitted patients, who have diverse, clinically complex problems (including ADEs) and who are taking highrisk medications while awaiting transfer to the ward (with further potential for ADEs) - mean that the volume of patients frequently exceeds the capacity of the health care practitioners caring for them. ED nurses must frequently administer potentially dangerous medications, and medication orders may be given verbally in critical patient situations. ${ }^{18}$ Medication errors can occur because of the high patient-nurse ratios, nurses' inability to properly check medicines being administered, nurses' fatigue secondary to high patient volume, and therefore the possibility of nurses forgetting to administer medications. One study showed that ED nurses administered medications in a less timely manner than ward nurses for boarded (admitted) patients, ${ }^{18}$ the most common reason being "insufficient time". In that study, medication reviews and intervention by EPhs ensured that medication administration complied with the orders prescribed. ${ }^{18}$ In addition, the provision of education about time-sensitive medications to other health professionals, such as timely administration of antibiotics for patients with sepsis, can improve patient outcomes.

In conclusion, as the volume of patients admitted from the $\mathrm{ED}$ increases with $\mathrm{ED}$ overcrowding, prioritization of these patients by the EPh is important for the safe and prompt treatment of these patients. EPhs are integral to ED medical teams, and ideally they should provide pharmaceutical care to all patients, regardless of admission status. However, because of funding constraints, only $39 \%$ of Canadian hospitals had at least 0.5 fulltime equivalent clinical pharmacy services personnel in the ED. ${ }^{19}$ Therefore, until adequate pharmacy staffing is available in the ED, prioritization of those at highest risk of medication errors-who are often inpatients awaiting transfer to the ward-is crucial in the provision of care.

\section{References}

1. Bond CA, Raehl CL. Clinical pharmacy services, pharmacy staffing, and hospital mortality rates. Pharmacotherapy. 2007;27(4):481-93.

2. Lada P, Delgado G Jr. Documentation of pharmacists' interventions in an emergency department and associated cost avoidance. Am J Health Syst Pharm. 2007;64(1):63-8.

3. Hughes DW, Roth JM, Laurel Y. Establishing emergency department pharmacy services. Am J Health Syst Pharm. 2010;67(13):1053-7.

4. Committee on the Future of Emergency Care in the United States Health System; Board on Health Care Services. Hospital-based emergency care: at the breaking point. Washington (DC): National Academies Press, Institute of Medicine; 2006 [cited 2018 Aug 24]. Available from: https://www.nap.edu/ catalog/11621/hospital-based-emergency-care-at-the-breaking-point

5. Rothschild JM, Churchill W, Erickson A, Munz K, Schuur JD, Salzberg CA, et al. Medication errors recovered by emergency department pharmacists. Ann Emerg Med. 2010;55(6):513-21.

6. Trends in acute inpatient hospitalizations and emergency department visits. Ottawa (ON): Canadian Institute for Health Information; 2015 [cited 2018 Aug 24]. Available from: https://secure.cihi.ca/estore/productSeries.htm?pc $=$ PCC526
7. ASHP Council on Pharmacy Practice. ASHP statement on pharmacy services to the emergency department. Am J Health Syst Pharm. 2008;65(24):2380-3.

8. Brown JN, Barnes CL, Beasley B, Cisneros R, Pound M, Herring C. Effect of pharmacists on medication errors in an emergency department. Am J Health Syst Pharm. 2008;65(4):330-3.

9. Roman C, Edwards G, Dooley M, Mitra B. Roles of the emergency medicine pharmacist: a systematic review. Am J Health Syst Pharm. 2018;75(11):796-806.

10. Taylor SE, Thompson B, Garrett K, et al. Comprehensive evaluation of the role of a clinical pharmacist in the emergency department. Quality improvement funding final report. Melbourne (Australia): Department of Human Services; 2003.

11. Zed PJ. Drug-related visits to the ED.J Pharm Pract. 2005;18(5):329-35.

12. Hohl CM, Zed PJ, Brubacher JR, Abu-Laban RB, Loewen PS, Purssell RA. Do emergency physicians attribute drug-related emergency department visits to medication-related problems? Ann Emerg Med. 2010;55(6):493-502.

13. Forster AJ, Asmis TR, Clark HD, Al Saied G, Code CC, Caughey SC. Ottawa Hospital Patient Safety Study: incidence and timing of adverse events in patients admitted to a Canadian teaching hospital. CMAJ. 2004; 170(8):1235-40.

14. Jacknin G, Nakamura T, Smally AJ, Ratzan RM. Using pharmacists to optimize patient outcomes and costs in the ED. Am J Emerg Med. 2014; 32(6):673-7.

15. Emergency department. In: Qmentum program standards. Version 12. Ottawa $(\mathrm{ON})$ : Accreditation Canada; 2017.

16. Carter MK, Allin DM, Scott LA, Grauer D. Pharmacist-acquired medication histories in a university hospital emergency department. Am J Health Syst Pharm. 2006;63(24):2500-3.

17. Wanbon R, Lyder C, Villeneuve E, Shalansky S, Manuel L, Harding M. Medication reconciliation practices in Canadian emergency departments: a national survey. Can J Hosp Pharm. 2015;68(3):202-9.

18. Jellinek SP, Cohen V, Fancher LB, Likourezos A, Lyke M, Peterson K, et al. Pharmacist improves timely administration of medications to boarded patients in the emergency department. J Emerg Nurs. 2010;36(2):105-10.

19. Wanbon R, Lyder C, Villeneuve E, Shalansky S, Manuel L, Harding M. Clinical pharmacy services in Canadian emergency departments: a national survey. Can J Hosp Pharm. 2015;68(3):191-201.

Cindy San, BScPharm, PharmD, ACPR

Clinical Pharmacy Specialist - Emergency

St Paul's Hospital

Vancouver, British Columbia

Competing interests: None declared.

\section{THE "CON" SIDE}

For most pharmacists, stepping into the emergency department (ED) can feel like stepping into the jungle: scary, unpredictable, and chaotic. These feelings are justified. The ED is a fast-paced, complex environment with a diverse population (ambulatory to critical care, pediatrics to geriatrics, medical to surgical, and involving resuscitations and traumas). ${ }^{1}$ The ED is particularly prone to medication errors given the high volume of patients, frequent interruptions, high frequency of verbal orders, and common use of high-risk medications. ${ }^{2}$ To enhance the quality of care and the safety of drug delivery in the $\mathrm{ED}$, an emergency pharmacist (EPh) must fulfill a unique role that is different from those of both ambulatory and inpatient pharmacists. To optimize this role, the EPh should prioritize 
the care of non-admitted patients (i.e., ambulatory patients not requiring admission and patients who are ill enough to require admission but have not yet been formally admitted to a hospital service).

Other countries have recognized the $\mathrm{ED}$ as a unique clinical environment and have developed guidelines for $\mathrm{EPh}$ roles. The American Society of Health-System Pharmacists (ASHP) lists medication order review, drug information, and patient care involving high-risk medications and procedures as priorities for the $\mathrm{EPh}$, placing lower importance on medication reconciliation and care of admitted patients. ${ }^{3}$ When $\mathrm{EPh}$ staffing is insufficient (e.g., when only a single $\mathrm{EPh}$ is present in the $\mathrm{ED}$, as is the case for most of Canadian hospitals ${ }^{4}$ ), the ASHP recommends that the ward pharmacist, not the $\mathrm{EPh}$, be accountable for admitted patients remaining within the ED. ${ }^{3}$ Similarly, the practice standards of the Society of Hospital Pharmacists of Australia advocate for the prioritization of patients at greatest risk of adverse drug reactions, with lower priority being given to admitted patients provided they can be assessed by the ward pharmacist within $24 \mathrm{~h}^{5}$

In Canada, the role of the EPh is still relatively new. The Canadian Society of Hospital Pharmacists has not developed any guidelines for the $\mathrm{EPh}$ role, and standardization is lacking. A recent survey of Canadian EPhs revealed a wide range of activities performed, with heavy emphasis on medication reconciliation and care of admitted patients. ${ }^{4}$ The lack of ED specialty residencies and role models, and a paucity of emergency medicine training in Canadian pharmacy curricula may limit pharmacists' confidence to care for non-admitted patients. The reported activities may reflect pharmacists' familiarity and comfort, rather than what's in the best interest of the $\mathrm{ED}$ and its patients.

By prioritizing the care of admitted patients, EPhs miss the opportunity to intervene with the assessment, prescribing, administration, and monitoring of all mediations administered by the ED team. The literature suggests that both the quality and safety of care of ED patients are improved when EPhs are involved as early as possible in the ED visit (Box 1). ${ }^{6-13}$ The EPh improves outcomes through involvement in traumas, resuscitations, and the care of patients requiring time-sensitive medications before the decision to admit. These patients often have multiple non-drug-related issues requiring physician and nursing care, such that without involvement of an EPh focusing on the optimization of medications, drug therapy issues may be overlooked by the rest of the team. The clinically significant end points in Box 1 can be achieved only when the EPh is available throughout the assessment and care of these critically ill patients before their admission.

EPhs can also facilitate positive outcomes through their care of less acutely ill patients who are likely to be discharged home. For example, more than 1 in $9 \mathrm{ED}$ visits are drug-related, but only one-third of the affected patients are admitted to hospital ${ }^{14}$; the remaining two-thirds would benefit from assessment by an $\mathrm{EPh}$. As another example, in the absence of interaction with an $\mathrm{EPh}$, the drug therapy of non-admitted patients may not be assessed until a later visit to a community pharmacist, who will not have access to the

\section{Box 1. Quality and Safety Outcomes of Selected Emergency Pharmacist Activities}

Trauma
- Decreased time to postintubation sedation (by 19 min) and
analgesia (by 23 min)
- Improved appropriateness of antibiotics for type 3 open fractures
$(74 \% \text { versus } 29 \%)^{7}$
Resuscitation
- Higher survival to hospital admission $(25 \% \text { versus } 17.8 \%)^{8}$
- 13 -fold reduction in errors during trauma and resuscitation ${ }^{9}$
Stroke
- 20 -min reduction in time to thrombolysis ${ }^{10}$
Sepsis
- $20 \%$ improvement in appropriateness of empiric antibiotics
- $44-m i n$ reduction in time to first antibiotics

hospital medical record and laboratory results. When EPhs review ED discharge prescriptions, they may intervene in up to $10 \%$ of cases. ${ }^{15}$ Outcomes are also improved when EPhs provide discharge education targeting high-risk medications such as opioids ${ }^{16}$ and anticoagulants. ${ }^{17}$

When EPhs are freed from caring for admitted patients, a door opens upon new opportunities. Many innovative EPh-led programs have been described in which an $\mathrm{EPh}$ takes on nontraditional roles as a value-added service to the health care system. EPh-driven programs have led to a $50 \%$ decrease in time to administration of prothrombin complex concentrate in patients with warfarinassociated hemorrhage ${ }^{18}$ and to discontinuation of antibiotics for $55 \%$ of patients without a urinary tract infection (as determined by postdischarge culture review). ${ }^{19}$ Safe and effective patient outcomes have also been demonstrated when EPhs managed phenytoin dosing ${ }^{20}$ and influenza vaccination $\mathrm{s}^{21}$ or led a venous thromboembolism clinic. ${ }^{22}$

In summary, EPhs are not simply inpatient pharmacists located in the ED. Medication reconciliation and assessment of admitted patients can be done by other members of the pharmacy team, and prioritizing admitted patients impedes the EPh's ability to perform value-added activities. Each $\mathrm{ED}$ is unique, and $\mathrm{EPhs}$ should work with physician, nursing, and pharmacy leaders to identify departmental priorities and determine how they can best improve the quality and safety of ED care. It is time to expand our conceptions of the $\mathrm{EPh}$ role. Together, let's lace up our boots and bravely go deeper into that jungle.

\section{References}

1. Morgan SR, Acquisto NM, Coralic Z, Basalyaga V, Campbell M, Kelly JJ, et al. Clinical pharmacy services in the emergency department. Am J Emerg Med. 2018;36(10):1727-32.

2. Ramlakhan S, Qayyum H, Burke D, Brown R. The safety of emergency medicine. Emerg Med J. 2016;33(4):293-9.

3. Eppert HD, Reznek AJ; ASHP Section of Clinical Specialists; Scientists Advisory Group on Emergency Care. ASHP guidelines on emergency medicine pharmacist services. Am J Health Syst Pharm. 2011;68(23):e81-95.

4. Wanbon R, Lyder C, Villeneuve E, Shalansky S, Manuel L, Harding M. Clinical pharmacy services in Canadian emergency departments: a national survey. Can J Hosp Pharm. 2015;68(3):191-201. 
5. SHPA Committee of Specialty Practice in Emergency Medicine; Fitzgerald C, Welch S, Taylor S, Harding A, Graudins L, Lawrence D, et al. SHPA standards of practice in emergency medicine pharmacy practice. J Pharm Pract Res. 2015;45(4):423-30.

6. Amini A, Faucett EA, Watt JM, Amini R, Sakles JC, Rhee P, et al. Effect of a pharmacist on timing of postintubation sedative and analgesic use in trauma resuscitations. Am J Health Syst Pharm. 2013;70(16):1513-7.

7. Harvey S, Hall AB, Wilson K. Impact of an emergency medicine pharmacist on initial antibiotic prophylaxis for open fractures in trauma patients. $\mathrm{AmJ}$ Emerg Med. 2018;36(2):290-3.

8. McAllister MW, Chestnutt JG. Improved outcomes and cost savings associated with pharmacist presence in the emergency department. Hosp Pharm. 2017;52(6):433-7.

9. Ernst AA, Weiss SJ, Sullivan A, Sarangarm D, Rankin S, Fees M, et al. On-site pharmacists in the ED improve medical errors. Am J Emerg Med. 2012;30(5):717-25.

10. Rech MA, Bennett S, Donahey E. Pharmacist participation in acute ischemic stroke decreases door-to-needle time to recombinant tissue plasminogen activator. Ann Pharmacother. 2017;51(12):1084-9.

11. Jacoby JS, Draper HM, Dumkow LE, Farooq MU, DeYoung GR, Brandt KL. Emergency medicine pharmacist impact on door-to-needle time in patients with acute ischemic stroke. Neurohospitalist. 2018;8(2):60-5.

12. Moussavi K, Nikitenko V. Pharmacist impact on time to antibiotic administration in patients with sepsis in an ED. Am J Emerg Med. 2016; 34(11):2117-21.

13. Attwood RJ, Garofoli AC, Beaudoin MR, Smith VD, Woloszyn AV, Berg $\mathrm{AK}$, et al. Impact of emergency department clinical pharmacist response to an automated electronic notification system on timing and appropriateness of antimicrobials in severe sepsis or septic shock in the emergency department [abstract 332]. Ann Emerg Med. 2012;60(4S):S118.

14. Zed PJ, Abu-Laban RB, Balen RM, Loewen PS, Hohl CM, Brubacher JR, et al. Incidence, severity and preventability of medication-related visits to the emergency department: a prospective study. CMAJ. 2008;178(12):1563-9.

15. Cesarz JL, Steffenhagen AL, Svenson J, Hamedani AG. Emergency department discharge prescription interventions by emergency medicine pharmacists. Ann Emerg Med. 2013;61(2):209-14.
16. Winstanley EL, Mashni R, Schnee S, Miller N, Mashni SM. The development and feasibility of a pharmacy-delivered opioid intervention in the emergency department. J Am Pharm Assoc (2003). 2017;57(2S):S87-91.

17. Zdyb EG, Courtney DM, Malik S, Schmidt MJ, Lyden AE. Impact of discharge anticoagulation education by emergency department pharmacists at a tertiary academic medical center. J Emerg Med. 2017;53(6):896-903.

18. Corio JL, Sin JH, Hayes BD, Goldstein JN, Fuh L. Impact of a pharmacistdriven prothrombin complex concentrate protocol on time to administration in patients with warfarin-associated intracranial hemorrhage. West J Emerg Med. 2018;19(5):849-54.

19. Zhang X, Rowan N, Pflugeisen BM, Alajbegovic $S$. Urine culture guided antibiotic interventions: a pharmacist driven antimicrobial stewardship effort in the ED. Am J Emerg Med. 2017;35(4):594-8.

20. Zed PJ, Filiatrault L. Clinical outcomes and patient satisfaction of a pharmacist-managed, emergency department-based outpatient treatment program for venous thromboembolic disease. Can J Hosp Pharm. 2008; 10(1):10-7.

21. Brancaccio A, Giuliano C, McNorton K, Delgado G. Impact of a phenytoin loading dose program in the emergency department. Am J Health Syst Pharm. 2014;71(21):1862-9.

22. Cohen V, Jellinek-Cohen SP, Likourezos A, Lum D, Zimmerman DE, Willner MA, et al. Feasibility of a pharmacy-based influenza immunization program in an academic emergency department. Ann Pharmacother. 2013; 47(11): 1140-7.

Anne Sylvestre, BScPhm, PharmD, ACPR

Inpatient Pharmacy

St Michael's Hospital

Toronto, Ontario

Competing interests: None declared. 